Article

\title{
Determining number of sites on ceria stabilizing single atoms via metal nanoparticle redispersion
}

\author{
Aisulu Aitbekova †, Cody J. Wrasman †, Andrew R. Riscoe, Larissa Y. Kunz, Matteo Cargnello* \\ Department of Chemical Engineering and SUNCAT Center for Interface Science and Catalysis, Stanford University, Stanford, California 94305, United \\ States
}

\section{A R T I C L E I N F}

Article history:

Received 1 August 2019

Accepted 12 September 2019

Published 5 June 2020

\section{Keywords:}

Ceria

Single-atom catalyst

Oxygen vacancies

$\mathrm{CO}_{2}$ hydrogenation

Redispersion

\begin{abstract}
A B S T R A C T
Single atom catalysts have recently attracted interest due to their maximization of the utilization of expensive noble metals as well as their unique catalytic properties. Based on its surface atomic properties, $\mathrm{CeO}_{2}$ is one of the most common supports for stabilizing single metal atoms. Many single atom catalysts are limited in their metal contents by the formation of metal nanoparticles once the catalyst support capacity for single atoms has been exceeded. Currently, there are no direct measurements to determine the capacity of a support to stabilize single atoms. In this work we develop a nanoparticle-based technique that allows for quantification of that capacity by redispersing Ru nanoparticles into single atoms and taking advantage of the different catalytic properties of $\mathrm{Ru}$ single atoms and nanoparticles in the $\mathrm{CO}_{2}$ hydrogenation reaction. This method avoids complications in metal loading caused by counterions in incipient wetness impregnation and can eventually be applied to a variety of different metals. Results using this technique follow trends in oxygen vacancy concentration and surface oxygen content and show promise as a new method for quantifying support single atom stabilization capacity.
\end{abstract}

(C) 2020, Dalian Institute of Chemical Physics, Chinese Academy of Sciences. Published by Elsevier B.V. All rights reserved.

\section{Introduction}

Single atom catalysts have attracted significant interest in recent years due to their ability to maximize the utilization of expensive noble metals [1,2] as well as the unique catalytic properties single atoms provide when compared to metal nanoparticles [3-7]. However, single atom catalysts are particularly vulnerable to agglomeration of metal atoms to form nanoparticles under reaction conditions [8]. It is also difficult to produce high metal loadings of single atoms to the exclusion of metal nanoparticles [8]. In order to become industrially relevant, procedures must be developed that are capable of producing high loadings of stable single atoms. Several groups have developed protocols to produce such catalysts with metal loadings as high as $3 \mathrm{wt} . \%$ active metal dispersed on a metal oxide support [8].

Work is emerging that suggests that the interaction between the isolated metal atom and the oxide support is critical both for the formation of a single atom catalyst as well as for that catalyst's long-term stability $[4,9,10]$. One support that has drawn significant interest is $\mathrm{CeO}_{2}$. Besides showing promise as a reducible support capable of activating oxidation catalysts [11-13], $\mathrm{CeO}_{2}$ has been shown to excel at stabilizing a wide variety of single metal atoms including Pt [1,10,14-16], Ru $[17,18], \mathrm{Pd}[5,19]$, and $\mathrm{Au}[15]$. It is hypothesized that $\mathrm{CeO}_{2}$ is able to stabilize single transition metal atoms in a square pocket of 4 oxygen atoms on the surface of $\mathrm{CeO}_{2}$ that is stable to high temperatures [10]. In fact, it has been suggested that the bond-

\footnotetext{
* Corresponding author. E-mail: mcargnello@stanford.edu

$\uparrow$ These authors contributed equally to this work.

DOI: S1872-2067(19)63504-7 | http://www.sciencedirect.com/science/journal/18722067 | Chin. J. Catal., Vol. 41, No. 6, June 2020
} 
ing energy of these single atoms in square pockets is stronger than in metal nanoparticles [10]. In this way, $\mathrm{CeO}_{2}$ provides single atoms sites stable to high temperatures, even at high metal loading $[8,9]$.

However, the exact number of sites on $\mathrm{CeO}_{2}$ capable of stabilizing single atoms remains difficult to quantify. Techniques exist to determine the concentration of oxygen on the $\mathrm{CeO}_{2}$ surface [20], as well as to quantify the amount of oxygen vacancies in $\mathrm{CeO}_{2}[18,21]$ but they are not yet capable of predicting the number of single atoms that can be stabilized by a given $\mathrm{CeO}_{2}$ support. In fact, it has been hypothesized that several different support sites may be capable of stabilizing single atoms, each with unique catalytic behaviors [14]. The determination of the number of each type of support site will be critical for future catalyst synthesis to ensure maximum single atom loading without the formation of less active metal nanoparticles.

Several recent works have shown that single atom catalysts can be generated by dispersing pre-formed colloidal nanoparticles $[16,17,22]$. Once the proper set of conditions are reached, nanoparticles will emit atoms that can be stabilized by the support. If there are sufficient sites for single atom stabilization, these catalysts can be transformed entirely into single atom catalysts [17]. However, if there are insufficient sites to stabilize all the emitted atoms, they eventually rejoin existing nanoparticles [19]. This technique has the benefit of tight control over the amount of metal added and fewer confounding factors for single atom stabilization such as counterions or ligands released from metal salt impregnation. The colloidal particle technique can also eventually be applied to a variety of metals that can be dispersed into single atoms [17] to provide comparisons in support stabilization capacity between metals.

In this work, we aim to leverage nanoparticle redispersion along with the unique catalysis of single atoms to develop a procedure for determining the number of sites capable of stabilizing single atoms that are contained in several different $\mathrm{CeO}_{2}$ samples. To do this we started with pre-formed Ru nanoparticles and dispersed them into single atoms using conditions from our previous work [17], tracking the products of $\mathrm{CO}_{2}$ hydrogenation as a function of metal loading. We then compared our experimental surface concentrations of Ru to several features of the $\mathrm{CeO}_{2}$ including surface area, surface

\section{Experimental}

\subsection{Materials}

Triruthenium dodecacarbonyl $\left(\mathrm{Ru}_{3}(\mathrm{CO})_{12}, 99 \%\right)$ and 1-oleylamine (OLAM, 70\%) were purchased from Sigma-Aldrich. Cerium oxide (98.5\%) was purchased from Treibacher Industrie AG and calcined at three different temperatures, 400,500 , and $600{ }^{\circ} \mathrm{C}$, for $5 \mathrm{~h}$ before use. All solvents were of reagent grade and all reagents were used as-received. All calcined supports and samples were ground and sieved below $180 \mu \mathrm{m}$ grain size.

\subsection{Synthesis of Ru NPS}

$\mathrm{Ru}$ NPs were prepared by thermal decomposition of $\mathrm{Ru}_{3}(\mathrm{CO})_{12}$ via colloidal synthesis using standard Schlenk techniques using a literature procedure with slight modifications [23]. For the synthesis of Ru NPs, $8 \mathrm{~mL}$ of OLAM were added to $40 \mathrm{mg}$ of $\mathrm{Ru}_{3}(\mathrm{CO})_{12}$ in a three-neck flask. The reaction solution was degassed ( $<2$ Torr) for $30 \mathrm{~min}$ at room temperature. The flask was then flushed with nitrogen, heated to $270{ }^{\circ} \mathrm{C}$ at a rate of $\sim 20{ }^{\circ} \mathrm{C} / \mathrm{min}$ and kept at this temperature for $30 \mathrm{~min}$. The particles were washed with $\sim 30 \mathrm{~mL}$ ethanol twice and recovered by centrifugation ( $8000 \mathrm{rpm}, 3 \mathrm{~min}$ ), and finally dispersed in hexanes. After the first washing, the NPs were first dispersed in $5 \mathrm{~mL}$ hexanes with the addition of 1-2 drops OLAM before adding ethanol. The concentration of $\mathrm{Ru}$ in the obtained solutions was determined by thermogravimetric analysis.

\section{3. $\mathrm{Ru}$ on $\mathrm{CeO}_{2}$ synthesis}

Catalysts were synthesized using the NPs described above along with $\mathrm{CeO}_{2}$ that had previously been calcined at 400, 500, and $600{ }^{\circ} \mathrm{C}$. In a typical synthesis, $1 \mathrm{~g}$ of $\mathrm{CeO}_{2}$ powder was dispersed in $10 \mathrm{~mL}$ hexanes using vigorous stirring. A solution of $\mathrm{Ru}$ NPs was then added to give the desired nominal weight loading. The mixture was then stirred for 5 min before the solvent was removed using a rotary evaporator. The collected powder was dried at room temperature overnight before being ground and sieved through a 180-mesh sieve. The organic ligands remaining on the NPs were removed using a rapid thermal treatment [24], where the powders were inserted into a furnace preheated to $700^{\circ} \mathrm{C}$ for $30 \mathrm{~s}$ in air.

\subsection{Catalyst characterization}

Transmission electron microscopy images were collected using an FEI Tecnai transmission electron microscope equipped with an Orius CCD operating at $200 \mathrm{kV}$. NPs in solution were examined by drop-casting solutions onto ultrathin carbon films supported on $\mathrm{Cu}$ (Electron Microscopy Sciences), while $\mathrm{Ru}$ on $\mathrm{CeO}_{2}$ catalysts was first dispersed in 2-propanol before drop-casting onto lacy-carbon films supported on $\mathrm{Cu}$ (Electron Microscopy Sciences). Particle size distributions were calculated by measuring at least 100 particles per sample using the ImageJ software. X-ray diffraction patterns were obtained using a PANalytical X'Pert PRO X-ray diffractometer in the $2 \theta$ range of $15^{\circ}$ to $85^{\circ}$ ( $\mathrm{Cu} K_{\alpha}$ radiation, $\lambda=1.5418 \AA$ ). Raman spectra of $\mathrm{CeO}_{2}$ were collected on a Horiba Xplora laser Raman microscope with $638 \mathrm{~nm}$ laser excitation. $\mathrm{N}_{2}$ physisorption experiments were carried out on a Micromeritics 3Flex instrument. For physisorption measurements, support powders were degassed under vacuum at $300{ }^{\circ} \mathrm{C}$ for $12 \mathrm{~h}$ prior to $\mathrm{N}_{2}$ adsorption at liquid nitrogen temperature. TPR measurements were conducted using $200 \mathrm{mg}$ of ceria in $25 \mathrm{~mL} / \mathrm{min}$ flow of (1 vol.\% $\mathrm{H}_{2}$ )/Ar. Temperature was increased from room temperature to $1000{ }^{\circ} \mathrm{C}$ with a ramp rate of $10^{\circ} \mathrm{C} / \mathrm{min}$, holding the sample at $1000{ }^{\circ} \mathrm{C}$ for $30 \mathrm{~min}$. Prior to TPR measurements, catalyst was pretreated in $\left(5 \mathrm{vol} . \% \mathrm{O}_{2}\right) / \mathrm{Ar}$ at $400{ }^{\circ} \mathrm{C}$.

\subsection{Catalytic activity testing}



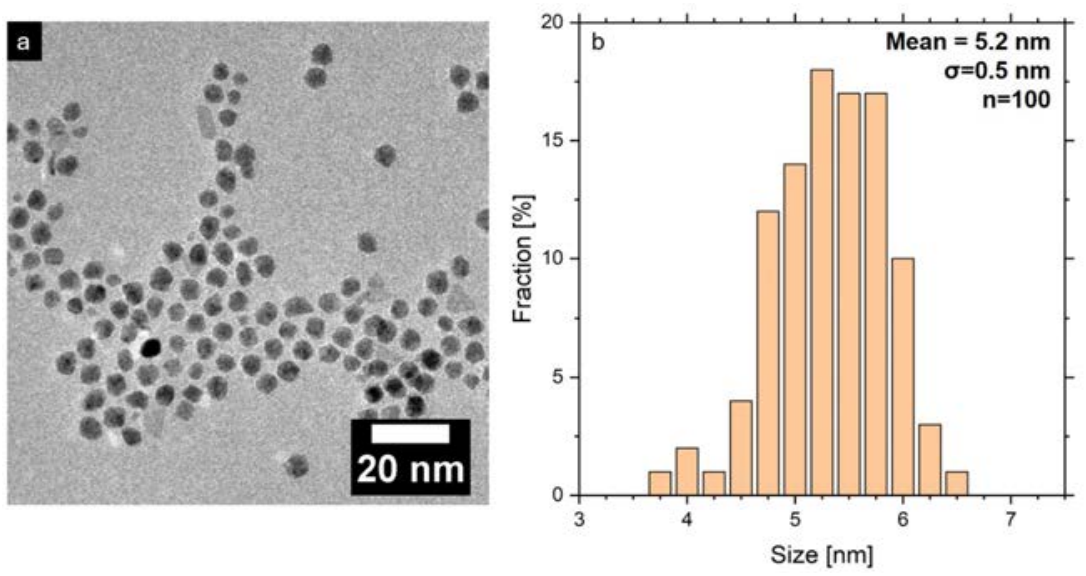

Fig. 1. Representative TEM image (a) and particle size distribution (b) of initial colloidal Ru nanoparticles.

Catalytic experiments were conducted under atmospheric pressure in a U-shaped quartz reactor with an internal diameter of $1 \mathrm{~cm}$. For $0.5 \mathrm{wt} . \% \mathrm{Ru} / \mathrm{CeO}_{2}$, approximately $20 \mathrm{mg}$ of catalyst powder was diluted with $\mathrm{Al}_{2} \mathrm{O}_{3}$ in a 1:10 dilution ratio, physically mixed and loaded into the reactor between two layers of granular acid-washed quartz. Amounts of samples with higher weight loading of $\mathrm{Ru}$ were adjusted to keep the same amount of metal. The reactor was heated by a Micrometrics Eurotherm 2416 furnace while the catalyst bed temperature was measured using a K-type thermocouple inserted in the middle of the reactor bed. The reaction mixture consisted of 1 vol. $\% \mathrm{CO}_{2}, 4$ vol. $\% \mathrm{H}_{2}$, with the balance Ar. Measurements were conducted at $235{ }^{\circ} \mathrm{C}$ and the gas-hourly space velocity (GHSV) was adjusted to maintain $\mathrm{CO}_{2}$ conversion below $5 \%$. Prior to catalytic activity testing, catalyst was oxidized in $\mathrm{O}_{2} \quad(5$ vol.\%)/Ar at $350{ }^{\circ} \mathrm{C}$ for $30 \mathrm{~min}$, then in $\mathrm{Ar}$ at $235^{\circ} \mathrm{C}$ for $10 \mathrm{~min}$, followed by reduction in $\mathrm{H}_{2}(5 \mathrm{vol} . \%) / \mathrm{Ar}$ at the same temperature for $30 \mathrm{~min}$.

\section{Results and discussion}

In order to probe the number of sites for single atom $\mathrm{Ru}$ stabilization we aimed to add precisely controlled amounts of $\mathrm{Ru}$ in the form of nanoparticles to several samples of $\mathrm{CeO}_{2}$. Nanoparticles were used as they allow for deposition of $\mathrm{Ru}$ without the addition of ligands or counterions found in metal salts that could skew the calculated number of sites in $\mathrm{CeO}_{2}$. After dispersing the nanoparticles into single atoms or mixtures of

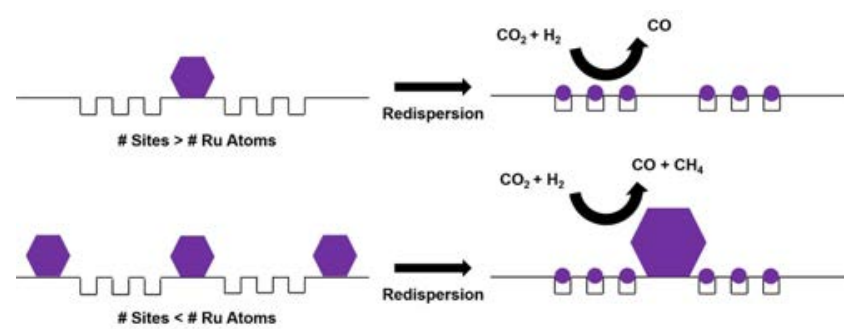

Scheme 1. Diagram demonstrating complete redispersion of low Ru NP loaded samples (above) and incomplete redispersion in high $\mathrm{Ru}$ NP loaded samples (below) as well as the products produced by these catalysts during $\mathrm{CO}_{2}$ hydrogenation catalysis. single atoms and nanoparticles using conditions we have described previously [17], we conducted $\mathrm{CO}_{2}$ hydrogenation using the product distribution of these tests to determine the Ru species present. In this method we assume that all available sites in $\mathrm{CeO}_{2}$ capable of stabilizing single $\mathrm{Ru}$ atoms are first filled by the dispersing atoms. Once these sites are filled, the remaining emitted atoms are assumed to rejoin existing nanoparticles or form new nanoparticles. A schematic of this proposed process is presented in Scheme 1.

To accomplish this goal, we synthesized colloidal $5 \mathrm{~nm} \mathrm{Ru}$ NPs following a process described previously in the literature [23]. A representative TEM image of these particles can be seen in Figure 1a along with a particle size distribution in Figure $2 \mathrm{~b}$. Both exhibit the high degree of uniformity in NP size possible with this colloidal synthesis technique. After determining the NP solution concentration using thermogravimetric analysis, the NPs were then immobilized on a series of $\mathrm{CeO}_{2}$ supports that had previously been calcined at 400,500 , and $600^{\circ} \mathrm{C}$ in air. The supports were characterized prior to NP addition using X-ray diffraction shown in Figure 2 along with a diffraction standard for $\mathrm{CeO}_{2}$. All samples showed the expected diffractions with no signs of secondary phases. Using the Scherrer

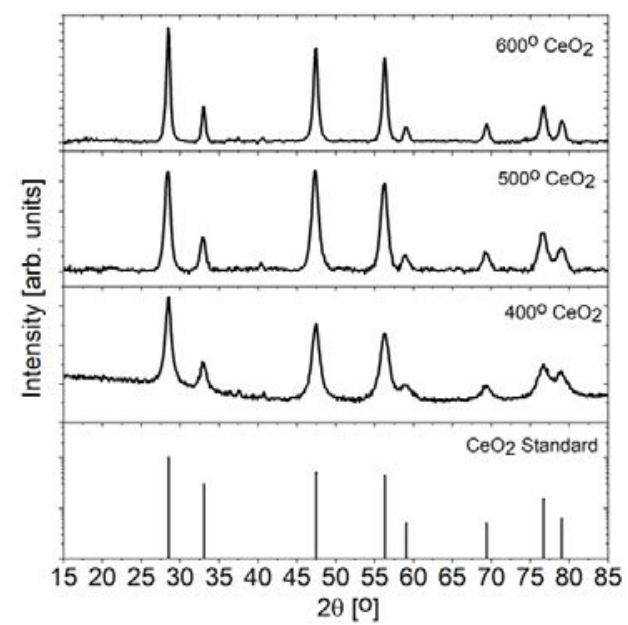

Fig. 2. XRD patterns of $\mathrm{CeO}_{2}$ calcined at 400,500 , and $600{ }^{\circ} \mathrm{C}$ along with a $\mathrm{CeO}_{2}$ standard. 


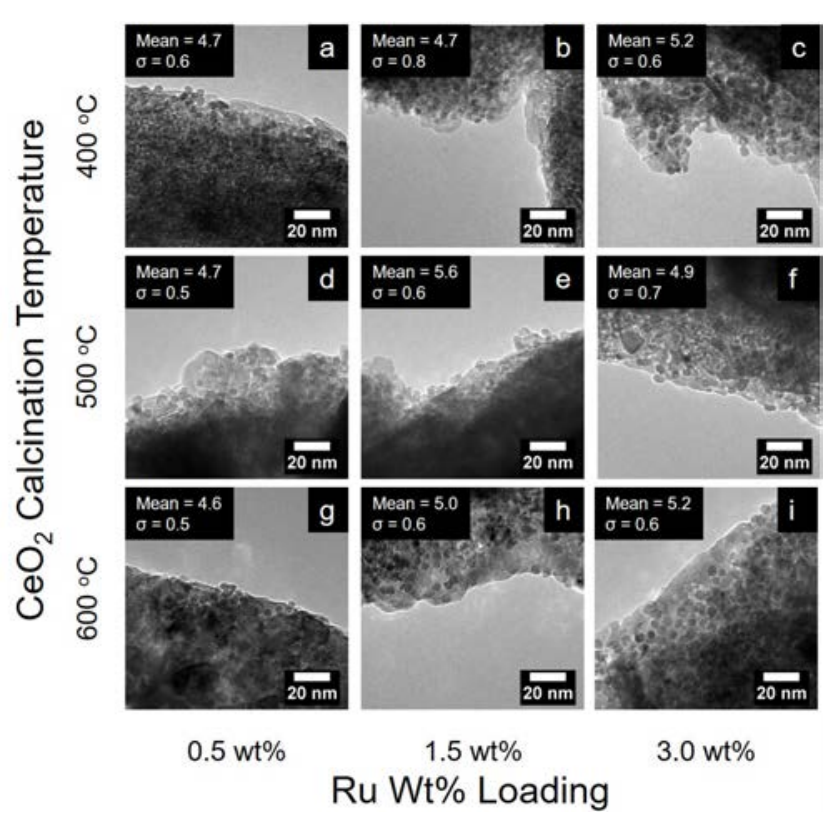

Fig. 3. Representative TEM images of several weight loadings of Ru NP supported on $\mathrm{CeO}_{2}$ calcined at several different temperatures (a-i). Each image includes the mean particle size and standard deviation calculated from measuring 100 particles.

equation, the crystallite sizes were determined to be $8.0,8.9$, and $13.8 \mathrm{~nm}$ at 400,500 , and $600{ }^{\circ} \mathrm{C}$, respectively. The supports were also characterized using $\mathrm{N}_{2}$ physisorption, which determined that samples calcined at 400,500 , and $600{ }^{\circ} \mathrm{C}$ had surface areas of 96,80 , and $46 \mathrm{~m}^{2} / \mathrm{g}$, respectively.

In order to provide a broad range of Ru atom concentrations to populate $\mathrm{CeO}_{2}$ defects, $\mathrm{Ru}$ NPs were immobilized onto each calcination temperature of $\mathrm{CeO}_{2}$ at loadings of $0.5 \mathrm{wt} . \%, 1.5$ wt.\%, and $3 \mathrm{wt} . \%$ producing an initial set of nine samples. Synthesis ligands were removed following immobilization using a high temperature thermal treatment [24]. Representative TEM images of these catalysts after thermal treatment, along with relevant particle size distribution statistics, are shown in Figure 3. NP are only visible at the edge of catalyst grains due to the high z-contrast of $\mathrm{CeO}_{2}$. All catalysts maintained the initial $\mathrm{Ru}$ NP size throughout the catalyst synthesis process.

Once the catalysts were synthesized, they were diluted with calcined $\mathrm{Al}_{2} \mathrm{O}_{3}$ and loaded into a plug flow reactor. Dilution ratios were chosen such that all catalyst beds would contain the same mass of $\mathrm{Ru}$, regardless of $\mathrm{Ru}$ loading on $\mathrm{CeO}_{2}$. All samples were then pretreated in a flow of $5 \% \mathrm{O}_{2}$ in $\mathrm{Ar}$ at $350{ }^{\circ} \mathrm{C}$ for 30 min. Past studies have found that this high temperature oxidative treatment is capable of dispersing $\mathrm{Ru}$ nanoparticles into single atoms on $\mathrm{CeO}_{2}$ [17]. Following this oxidative treatment, the samples were cooled in $\mathrm{Ar}$ to $235{ }^{\circ} \mathrm{C}$ and reduced at the same temperature in $5 \% \mathrm{H}_{2}$ for $30 \mathrm{~min}$. It has been shown that this reducing treatment is insufficient to agglomerate dispersed Ru single atoms on $\mathrm{CeO}_{2}$ [17].

The reduced samples were then exposed to a reaction gas mixture containing $1 \% \mathrm{CO}_{2}$ and $4 \% \mathrm{H}_{2}$ in $\mathrm{Ar}$ and were allowed to equilibrate for up to $6 \mathrm{~h}$ until a steady state was reached. In all cases the CO selectivity increased during the approach to steady state, possibly due to deactivation of methanizing nanoparticles. Gas flow rates were modified to ensure that all measurements were conducted at a constant $\mathrm{CO}_{2}$ conversion of between $2 \%$ and $4 \%$, well within the differential regime. Gas chromatography only detected $\mathrm{CH}_{4}$ and $\mathrm{CO}$ as products of the reaction. The selectivity for $\mathrm{CO}$ for all catalysts is plotted in Figure 4 as a function of $\mathrm{Ru}$ loading. It was found that low loadings of $\mathrm{Ru}$ on both $400{ }^{\circ} \mathrm{C}$ and $500{ }^{\circ} \mathrm{C}$ calcined $\mathrm{CeO}_{2}$ were able to produce exclusively $\mathrm{CO}$. This selectivity is in line with previous reports that show that fully dispersed atoms of $\mathrm{Ru}$ [17] and other metals [6] are selective for CO production under $\mathrm{CO}_{2}$ hydrogenation conditions. However, at increasing weight loadings the $400{ }^{\circ} \mathrm{C}$ and $500{ }^{\circ} \mathrm{C}$ calcined $\mathrm{CeO}_{2}$ samples showed a selectivity shift towards $\mathrm{CH}_{4}$ production until it became the primary product at $3 \mathrm{wt} . \% \mathrm{Ru}$. To better illustrate where this selectivity change began, weight loadings of $0.75 \mathrm{wt} . \%, 1.0$ wt.\%, and 1.25 wt.\% were also synthesized on the $\mathrm{CeO}_{2}$ calcined at $500{ }^{\circ} \mathrm{C}$. These results are included in Figure $4 \mathrm{~b}$. The selectivity transition never occurred for the $600{ }^{\circ} \mathrm{C}$ calcined $\mathrm{CeO}_{2}$ which produced primarily $\mathrm{CH}_{4}$ at all $\mathrm{Ru}$ loadings, indicating a low ability to stabilize single $\mathrm{Ru}$ atoms.

It is unlikely that $\mathrm{Ru}$ atoms would migrate through the gas phase onto the $\mathrm{Al}_{2} \mathrm{O}_{3}$ used as a diluent during redispersion due to the high temperatures (over $700{ }^{\circ} \mathrm{C}$ ) needed to volatalize $\mathrm{Ru}$ [25]. However, to confirm that $\mathrm{Ru}$ atoms are not being stabilized as single atoms by the $\mathrm{Al}_{2} \mathrm{O}_{3}$ diluent, a control experiment was conducted where a pure bed of $3 \mathrm{wt}$. $\% \mathrm{Ru}$ on $\mathrm{CeO}_{2}$ calcined at $500{ }^{\circ} \mathrm{C}$ was compared to a diluted bed of the same catalyst with the same catalyst mass. In both cases CO selectivity was roughly $20 \%$. Had the Ru been stabilized as single atoms on the $\mathrm{Al}_{2} \mathrm{O}_{3}$ it would be expected that the overall $\mathrm{CO}$ selectivity would be greater, despite $\mathrm{Ru}$ single atoms on $\mathrm{Al}_{2} \mathrm{O}_{3}$ having a lower activity for $\mathrm{CO}_{2}$ hydrogenation [7].

These selectivity results are in line with different relative
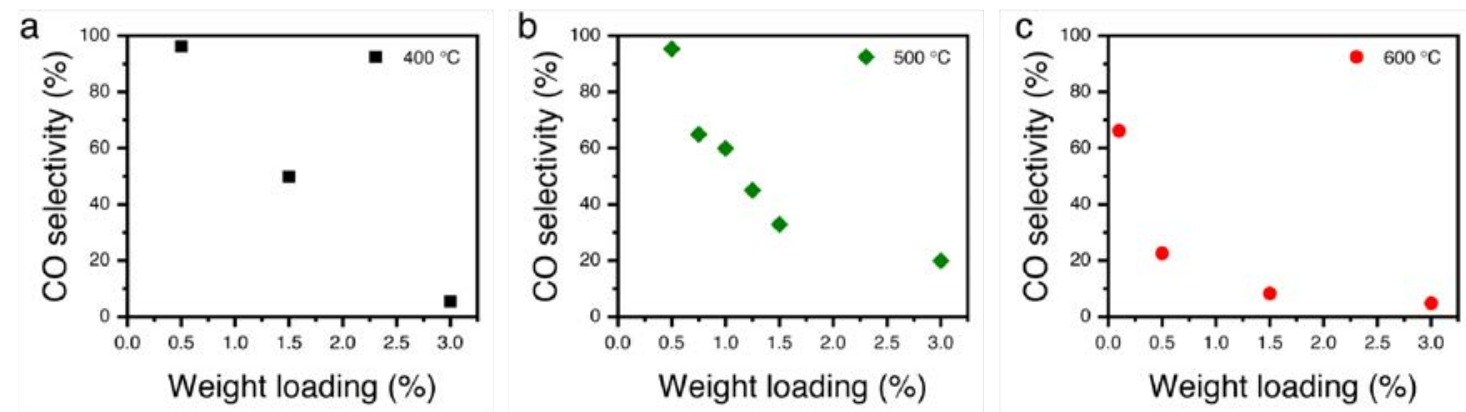

Fig. 4. Steady-state $\mathrm{CO}$ selectivity of $\mathrm{Ru} / \mathrm{CeO}_{2}$ catalysts made with $\mathrm{CeO}_{2}$ calcined at $400{ }^{\circ} \mathrm{C}(\mathrm{a}), 500{ }^{\circ} \mathrm{C}(\mathrm{b})$, and $600{ }^{\circ} \mathrm{C}(\mathrm{c})$. 

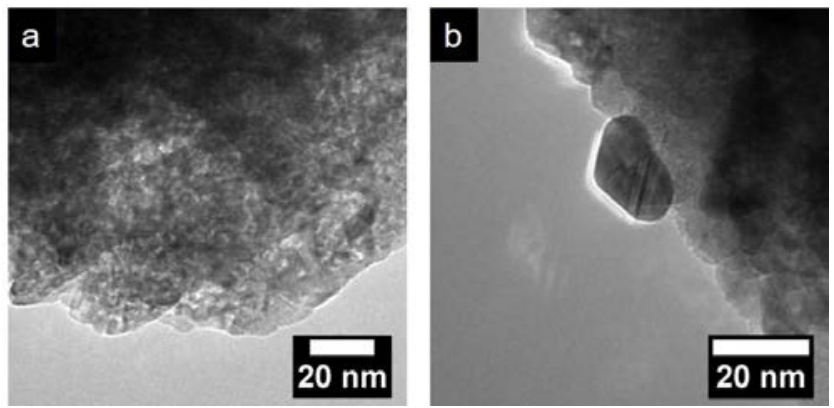

Fig. 5. TEM of 0.5 wt.\% $\mathrm{Ru} / \mathrm{CeO}_{2}$ (a) and 3.0 wt.\% $\mathrm{Ru} / \mathrm{CeO}_{2}$ (b) after catalysis at $235^{\circ} \mathrm{C}$.

populations of nanoparticles and single atoms being created at different Ru weight loadings and support areas. When the total number of $\mathrm{Ru}$ atoms is lower than the number of $\mathrm{CeO}_{2}$ sites able to host them, all Ru atoms remain isolated. However, once the number of $\mathrm{Ru}$ atoms exceeds the number of $\mathrm{CeO}_{2}$ sites, the $\mathrm{Ru}$ atoms unable to locate a stable site reattach to existing nanoparticles in an Ostwald ripening process. As a result, samples that contained fewer $\mathrm{Ru}$ atoms than $\mathrm{CeO}_{2}$ sites showed no distinguishable nanoparticles when observed using TEM (Figure $5 a)$ while those containing more $\mathrm{Ru}$ atoms than $\mathrm{CeO}_{2}$ sites contained large Ru agglomerates (Figure $5 b$ ). These observations are supported by previous studies that followed nanoparticle dispersion into single atoms $[8,19]$.

Using catalytic selectivity as an indicator, we attempted to quantify the number of single $\mathrm{Ru}$ atoms that could be stabilized by $\mathrm{CeO}_{2}$ calcined at several different temperatures. This was done by first assuming samples that were $100 \%$ selective to CO contained entirely dispersed atoms and that all Ru remained on the $\mathrm{CeO}_{2}$ surface. The second assumption is supported by several literature sources proposing that $\mathrm{Ru}$ can only be doped into $\mathrm{CeO}_{2}$ at temperatures exceeding $550{ }^{\circ} \mathrm{C}[26,27]$. Direct quantification of Ru remaining in the catalyst by ICP-OES was not possible due to the inability of aqua regia to solubilize $\mathrm{Ru}$. In cases where $\mathrm{CO}$ selectivity was $100 \%$, the total number of $\mathrm{Ru}$ atoms could be divided by the $\mathrm{CeO}_{2}$ surface area to estimate a density of sites and establish a lower bound to their concentration. The upper bound for this estimate could be calculated in the same way for the first weight loading of Ru that was not $100 \%$ selective to CO. In this way, a range of possible defect densities could be calculated and are shown in Table 1. No lower bound could be established for the $600{ }^{\circ} \mathrm{C}$ sample because there were no conditions under which the catalyst was

\section{Table 1}

BET surface area, number of Ru single atoms estimated from the catalytic results, relative concentration of oxygen vacancies determined from Raman measurements, and TPR integration results of ceria supports calcined at different temperatures.

\begin{tabular}{lccccc}
\hline $\begin{array}{l}\text { Calcination } \\
\text { temperature }\end{array}$ & $\begin{array}{c}\text { BET } \\
\text { surface } \\
\left({ }^{\circ} \mathrm{C}\right)\end{array}$ & $\begin{array}{c}\text { \# Ru single atoms per } \\
\text { area } \\
\left(\mathrm{m}^{2} / \mathrm{g}\right)\end{array}$ & $\begin{array}{c}I_{\mathrm{D}} / I_{\mathrm{F} 2 \mathrm{~g}} \\
\left(10^{17} \text { atoms } / \mathrm{m}^{2} \mathrm{Ce} 2\right)\end{array}$ & $\begin{array}{c}\text { Surface } \\
\text { ratio } \\
\text { from } \\
\text { oxygen } \\
\text { Raman }\end{array}$ & $\begin{array}{c}\min \\
\left(10^{17}\right.\end{array}$ \\
\hline 400 & 96 & 3.1 & $\max$ & & Rams $\left./ \mathrm{m}^{2} \mathrm{Ce} 2\right)$ \\
500 & 80 & 3.7 & 5.6 & 0.013 & 8.9 \\
600 & 46 & - & 6.5 & 0.007 & 8.8 \\
\hline
\end{tabular}

fully selective to CO. As a result, only an upper bound from the $0.5 \mathrm{wt} . \%$ sample could be calculated.

Despite the sharp selectivity differences between single $\mathrm{Ru}$ atoms and nanoparticles, their relative abundances cannot be calculated from selectivity alone. This is a result of several side reactions that can occur over Ru nanoparticles. For example, $\mathrm{Ru}$ nanoparticles are known to be active catalysts for the methanation of CO [28-30] as well as for the water gas shift reaction [31]. In fact, it has been shown that $\mathrm{Ru}$ nanoparticles methanize $\mathrm{CO}$ at a higher rate than they methanize $\mathrm{CO}_{2}$ [32]. As a result, a catalyst containing a population of both single atoms and nanoparticles will appear to contain more nanoparticles if populations are calculated through linear interpolation because the existing nanoparticles will consume $\mathrm{CO}$, concealing the presence of some single atoms. A further complication to using samples that were not completely selective to CO for determination of defect site density is that $\mathrm{Ru}$ atoms on the inside of nanoparticles are inactive. If the particle size was maintained during the redispersion process, these atoms could be accounted for. However, since the particle size increases unpredictably under redispersion conditions when there are not enough $\mathrm{CeO}_{2}$ sites to stabilize exclusively $\mathrm{Ru}$ single atoms, this calculation cannot be carried out accurately. As a result, the current method can only provide a range of vacancy concentrations. Increasing accuracy can be attained by testing smaller steps in Ru weight loading.

We then set out to compare our surface concentration results with several other techniques used to measure surface oxygen vacancies. First, we employed Raman spectroscopy, which has been used to determine the relative concentration of oxygen vacancies in $\mathrm{CeO}_{2}[18,21]$. Raman spectra of different ceria supports showed distinct features at $598 \mathrm{~cm}^{-1}$ that is assigned to oxygen vacancies and at $460-465 \mathrm{~cm}^{-1}$ that corresponds to the vibrational $\mathrm{F}_{2 \mathrm{~g}}$ mode of fluorite-type structure $[18,21]$ (Table 1, Figure 6). By integrating areas of the corresponding peaks and calculating the ratio $I_{\mathrm{D}} / I_{\mathrm{F} 2 \mathrm{~g}}$ for each sample, we obtained relative concentrations of oxygen species for each support. The higher the ratio, the larger the concentration of oxygen vacancies. The ratio of these peaks was quite similar for the samples calcined at 400 and $500{ }^{\circ} \mathrm{C}$ and significantly

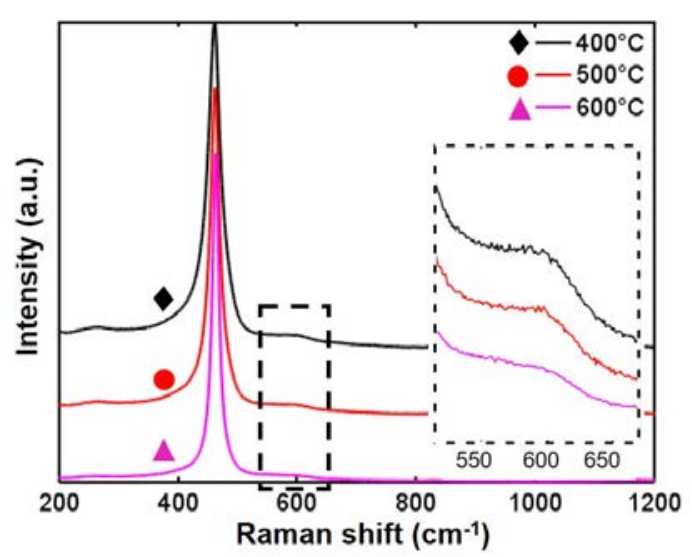

Fig. 6. Raman spectra of $\mathrm{CeO}_{2}$ calcined at various temperatures with the inset showing oxygen vacancy feature at $598 \mathrm{~cm}^{-1}$. 


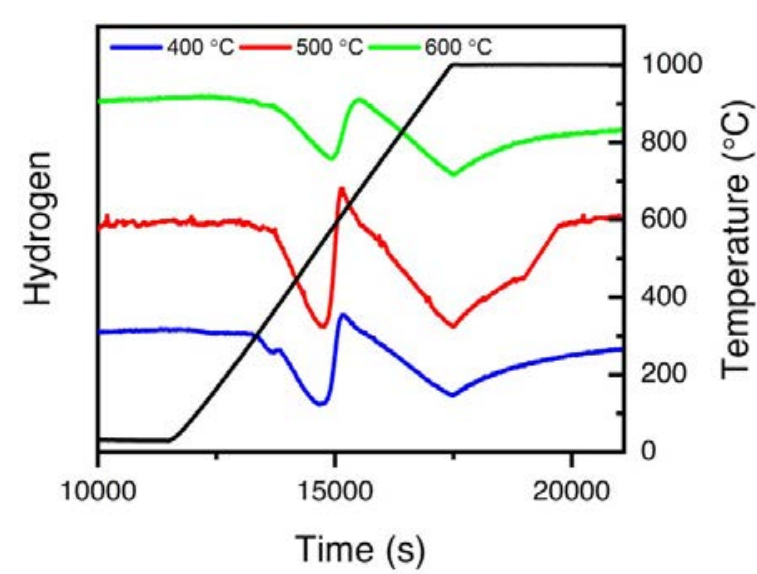

Fig. 7. Hydrogen TPR profiles of $\mathrm{CeO}_{2}$ calcined at various temperatures.

lower for the sample calcined at $600{ }^{\circ} \mathrm{C}$. The similarity between the results for 400 and $500{ }^{\circ} \mathrm{C}$ calcined $\mathrm{CeO}_{2}$ supports indicates that the two samples have similar concentrations of oxygen vacancies, which is higher than that of the $600^{\circ} \mathrm{C}$ calcined sample. This trend follows the catalytic results where the $\mathrm{CeO}_{2}$ calcined at 400 and $500{ }^{\circ} \mathrm{C}$ appeared to have similar capacities to host single atoms while the sample calcined at $600{ }^{\circ} \mathrm{C}$ could only host a much smaller number of single atoms. It is important to realize however, that with $\mathrm{CeO}_{2}$ supports on the order of $100 \mathrm{~nm}$, Raman is a bulk technique that cannot distinguish surface oxygen species, which are of the most interest for forming stable single atom catalysts.

To address this question, temperature programmed reduction (TPR) was employed. It is known that $\mathrm{CeO}_{2}$ surface oxygen will reduce at lower temperatures than oxygen in the bulk of $\mathrm{CeO}_{2}$ [20]. To monitor this reduction, we tracked hydrogen consumption by reaction with the oxygen of $\mathrm{CeO}_{2}$ as a function of temperature. In these profiles in Figure 7, two distinct peaks are observed. The peak at $500{ }^{\circ} \mathrm{C}$ corresponds to reduction of surface oxygen, while the peak at $1000{ }^{\circ} \mathrm{C}$ is related to reduction of bulk oxygen [33]. By integrating the first peaks we were able to calculate concentrations of surface oxygen (Table 1). This was accomplished by first determining the area of $\mathrm{H}_{2}$ consumed during the full reduction of a $\mathrm{CuO}$ standard. With this information, we were then able to convert all experimental hydrogen areas into moles of oxygen removed from the $\mathrm{CeO}_{2}$. Once this was known, the moles of oxygen from the surface peak could be distributed across the known surface area of the catalyst bed, resulting in the surface concentration found in Table 1.

Like the Raman results, the results in Table 1 follow a similar trend to the catalytic data where the samples calcined at 400 and $500{ }^{\circ} \mathrm{C}$ contained similar concentrations of surface oxygens while the sample at $600{ }^{\circ} \mathrm{C}$ contained much less. Interestingly, in the case of the samples calcined at 400 and $600{ }^{\circ} \mathrm{C}$, the concentration of surface oxygen falls within the range of possible single $\mathrm{Ru}$ atom concentrations. This finding supports the idea that single atoms can be hosted by oxygen at the $\mathrm{CeO}_{2}$ surface $[10,34]$. However, TPR results for the sample calcined at $500{ }^{\circ} \mathrm{C}$, where smaller $\mathrm{Ru}$ concentration steps were taken, provides a number of surface oxygens much higher than the range of surface $\mathrm{Ru}$ atoms that could be supported. This could suggest that not all surface oxygen sites are capable of hosting $\mathrm{Ru}$ due to other factors required for hosting single metal atoms. Recent work has shown that single sites with different conformations within the support can have different stabilities and activities [14], suggesting that some $\mathrm{CeO}_{2}$ surface sites may be unsuitable for stabilizing single atoms. As a result, it is not surprising that the amount of surface oxygen exceeds the maximum number of stabilized surface atoms because some surface oxygen may reside in sites unable to stabilize single atoms. In this case, the Ru redispersion test may prove to be more valuable for determining the capacity of a support to host single atoms than standard methods used for measuring surface oxygen concentrations and defects. Regardless, it is interesting to note that the surface concentration of oxygen in $\mathrm{CeO}_{2}$ is on the same order of magnitude as dispersible $\mathrm{Ru}$ atoms for all samples.

\section{Conclusions}

In this work we have shown a catalytic method for measuring sites capable of hosting single atoms. This was accomplished by taking advantage of the different catalytic selectivity of Ru single atoms and nanoparticles in the $\mathrm{CO}_{2}$ hydrogenation reaction. By monitoring the maximum $\mathrm{Ru}$ weight loading that provided only single atom selectivity, an estimate of the ability of a support to host single atoms could be calculated. Our estimations from catalysis followed trends exhibited by established methods for measuring surface oxygen content with samples showing less oxygen content also dispersing less Ru. Beyond matching trends, our method also provided estimates for Ru dispersion ability on the same order of magnitude as the surface oxygen concentration. Importantly, it appears that the amount of $\mathrm{Ru}$ that could be dispersed lies below the total amount of surface oxygen present on $\mathrm{CeO}_{2}$, possibly indicating other factors determining which sites Ru can occupy. Overall, the methods outlined in this paper are valuable for determining the number of singles atoms a support material can host which will have important consequences for the synthesis of future single atom catalysts.

\section{Acknowledgments}

We gratefully acknowledge support from the Stanford Precourt Institute for Energy. M.C. acknowledges support from the School of Engineering at Stanford University and from a Terman Faculty Fellowship. A.A. acknowledges support from a Stanford Graduate Fellowship (SGF) and an EDGE fellowship. Part of this work was performed at the Stanford Nano Shared Facilities (SNSF), supported by the National Science Foundation under award ECCS-1542152.

\section{References}

[1] J. Jones, H. Xiong, A. T. DeLaRiva, E. J. Peterson, H. Pham, S. R. Challa, G. Qi, S. Oh, M. H. Wiebenga, X. I. Pereira Hernandez, Y. Wang, A. K. Datye, Science, 2016, 353, 150-154. 


\section{Graphical Abstract}

Chin. J. Catal., 2020, 41: 998-1005 doi: S1872-2067(19)63504-7

Determining number of sites on ceria stabilizing single atoms via metal nanoparticle redispersion

Aisulu Aitbekova, Cody J. Wrasman, Andrew R. Riscoe, Larissa Y. Kunz, Matteo Cargnello*

Stanford University, USA

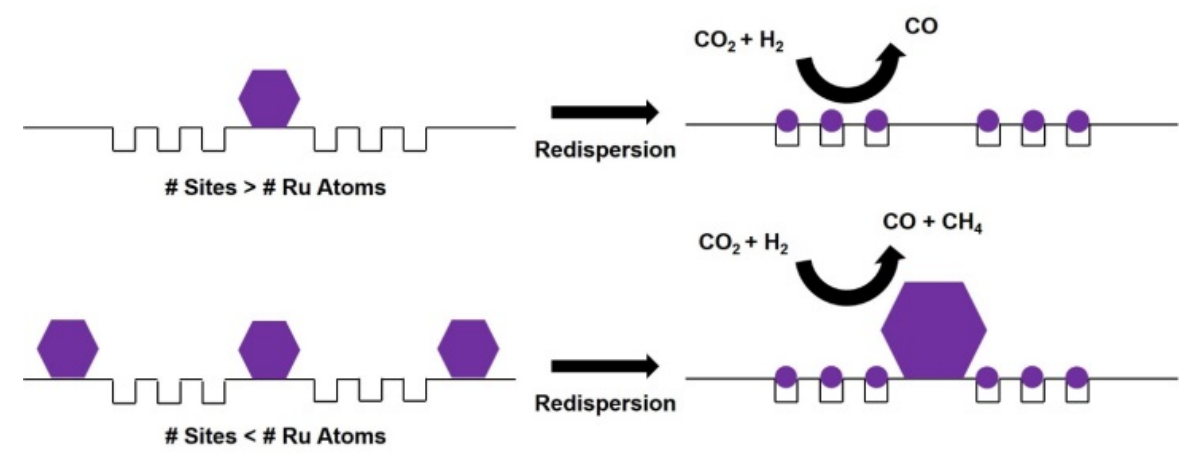

Redispersion of low Ru nanoparticles loaded samples leads to metal disintegration into highly dispersed species that serve as RWGS catalyst. Redispersion of high loaded samples forms both single atoms and nanoparticles that produce $\mathrm{CO}$ and $\mathrm{CH}_{4}$.

[2] L. DeRita, S. Dai, K. Lopez-Zepeda, N. Pham, G. W. Graham, X. Pan, P. Christopher, J. Am. Chem. Soc., 2017, 139, 14150-14165.

[3] Y. Lu, J. Wang, L. Yu, L. Kovarik, X. Zhang, A. S. Hoffman, A. Gallo, S. R. Bare, D. Sokaras, T. Kroll, V. Dagle, H. Xin, A. M. Karim, Nat. Catal., 2019, 2, 149-156.

[4] C. Gao, Z. Qi, B. Hong, M. Wang, J. Bao, F. Zhang, J. Ding, X. Zhu, S. Sun, Langmuir, 2015, 31, 1730-1736.

[5] P. Xin, J. Li, Y. Xiong, X. Wu, J. Dong, W. Chen, Y. Wang, L. Gu, J. Luo, H. Rong, C. Chen, Q. Peng, D. Wang, Y. Li, Angew. Chem. Int. Ed., 2018, $57,4642-4646$.

[6] J. H. Kwak, L. Kovarik, J. Szanyi, ACS Catal., 2013, 3, 2094-2100.

[7] J. H. Kwak, L. Kovarik, J. Szanyi, ACS Catal., 2013, 3, 2449-2455.

[8] D. Kunwar, S. Zhou, A. DeLaRiva, E. J. Peterson, H. Xiong, X. I. Pereira-Hernández, S. C. Purdy, R. ter Veen, H. H. Brongersma, J. T. Miller, H. Hashiguchi, L. Kovarik, S. Lin, H. Guo, Y. Wang, A. K. Datye, ACS Catal., 2019, 9, 3978-3990.

[9] J. A. Farmer, C. T. Campbell, Science, 2010, 329, 933-936.

[10] A. Bruix, Y. Lykhach, I. Matolínová, A. Neitzel, T. Skála, N. Tsud, M. Vorokhta, V. Stetsovych, K. Ševčíková, J. Mysliveček, R. Fiala, M. Václavu, K. C. Prince, S. Bruyère, V. Potin, F. Illas, V. Matolín, J. Libuda, K. M. Neyman, Angew. Chem. Int. Ed., 2014, 53, 10525-10530.

[11] A. Beck, A. C. Yang, A. R. Leland, A. R. Riscoe, F. A. Lopez, E. D. Goodman, M. Cargnello, AIChE J., 2018, 64, 3159-3167.

[12] M. Cargnello, C. Gentilini, T. Montini, E. Fonda, S. Mehraeen, M. Chi, M. Herrera-Collado, N. D. Browning, S. Polizzi, L. Pasquato, P. Fornasiero, Chem. Mater., 2010, 22, 4335-4345.

[13] M. Cargnello, V. V. T. Doan-Nguyen, T. R. Gordon, R. E. Diaz, E. A. Stach, R. J. Gorte, P. Fornasiero, C. B. Murray, Science, 2013, 341, 771-773.

[14] L. DeRita, J. Resasco, S. Dai, A. Boubnov, H. V. Thang, A. S. Hoffman, I. Ro, G. W. Graham, S. R. Bare, G. Pacchioni, X. Pan, P. Christopher, Nat. Mater., 2019, 18, 746-751.

[15] Q. Fu, H. Saltsburg, M. Flytzani-stephanopoulos, Science, 2003, 301, 935-938.
[16] A. M. Gänzler, M. Casapu, P. Vernoux, S. Loridant, F. J. Cadete Santos Aires, T. Epicier, B. Betz, R. Hoyer, J. D. Grunwaldt, Angew. Chem. Int. Ed., 2017, 56, 13078-13082.

[17] A. Aitbekova, L. Wu, C. J. Wrasman, A. Boubnov, A. S. Hoffman, E. D. Goodman, S. R. Bare, M. Cargnello, J. Am. Chem. Soc., 2018, 140, 13736-13745.

[18] Y. Guo, S. Mei, K. Yuan, D. J. Wang, H. C. Liu, C. H. Yan, Y. W. Zhang, ACS Catal., 2018, 8, 6203-6215.

[19] E. D. Goodman, A. C. Johnston-Peck, E. M. Dietze, C. J. Wrasman, A. S. Hoffman, F. Abild-Pedersen, S. R. Bare, P. N. Plessow, M. Cargnello, Nat. Catal., 2019, 2, 748-755.

[20] E. Mamontov, T. Egami, R. Brezny, M. Koranne, S. Tyagi, J. Phys. Chem. B, 2002, 104, 11110-11116.

[21] M. Guo, J. Lu, Y. Wu, Y. Wang, M. Luo, Langmuir, 2011, 27, 3872-3877.

[22] S. Wei, A. Li, J. C. Liu, Z. Li, W. Chen, Y. Gong, Q. Zhang, W. C. Cheong, Y. Wang, L. Zheng, H. Xiao, C. Chen, D. Wang, Q. Peng, L. Gu, X. Han, J. Li, Y. Li, Nat. Nanotechnol., 2018, 13, 856-861.

[23] M. Vanden Brink, M. A. Peck, K. L. More, J. D. Hoefelmeyer, J. Phys. Chem. C, 2008, 112, 12122-12126.

[24] M. Cargnello, C. Chen, B. T. Diroll, V. V. T. Doan-Nguyen, R. J. Gorte, C. B. Murray, J. Am. Chem. Soc., 2015, 137, 6906-6911.

[25] F. Garisto, AECL-9552, Whiteshell Nuclear Research Establishment, Manitoba, Canada, 1988.

[26] S. Sharma, Z. Hu, P. Zhang, E. W. McFarland, H. Metiu, J. Catal,, 2011, 278, 297-309.

[27] D. C. Upham, A. R. Derk, S. Sharma, H. Metiu, E. W. McFarland, Catal. Sci. Technol., 2015, 5, 1783-1791.

[28] I. Leith, J. Catal., 1985, 91, 283-292.

[29] I. R. Leith, J. Chem. Soc., Chem. Commun., 1983, 2, 93-94.

[30] Z. Mohamed, V. D. B. C. Dasireddy, S. Singh, H. B. Friedrich, Int. J. Hydrogen Energy, 2018, 43, 22291-22302.

[31] R. Stepić, C. R. Wick, V. Strobel, D. Berger, N. Vučemilović-Alagić, M. Haumann, P. Wasserscheid, A. S. Smith, D. M. Smith, Angew. Chem. Int. Ed., 2019, 58, 741-745. 
[32] P. Garbis, C. Kern, A. Jess, Energies, 2019, 12, 1-15.

[33] J. Xu, J. Harmer, G. Li, T. Chapman, P. Collier, S. Longworth, S. C. Tsang, Chem. Commun., 2010, 46, 1887-1889.
[34] A. Neitzel, A. Figueroba, Y. Lykhach, T. Skála, M. Vorokhta, N. Tsud, S. Mehl, K. Ševčíková, K. C. Prince, K. M. Neyman, V. Matolín, J. Libuda, J. Phys. Chem. C, 2016, 120, 9852-9862.

\title{
金属纳米粒子再分散法测定二氧化铈稳定的单原子的位点数
}

\author{
Aisulu Aitbekova ${ }^{\dagger}$, Cody J. Wrasman ${ }^{\dagger}$, Andrew R. Riscoe, Larissa Y. Kunz, Matteo Cargnello * \\ 斯坦福大学化学工程系, 界面科学与催化SUNCAT中心, 加利福尼亚94305, 美国
}

摘要: 单原子催化剂由于能最大限度地利用贵金属以及其独特的催化性能而引起了人们的兴趣. 基于其表面原子性质, $\mathrm{CeO}_{2}$ 是稳定单金属原子最常用的载体之一. 一旦金属含量超过其负载的载体容量, 就会形成金属纳米粒子, 因而许多单原 子催化剂的金属含量受限. 目前, 还没有直接的测量方法来确定载体稳定单个原子的容量. 本文开发了一种基于纳米颗粒 的技术, 即通过将Ru纳米颗粒重新分散成单个原子, 并利用 $\mathrm{Ru}$ 单原子和纳米颗粒在 $\mathrm{CO}_{2}$ 加氢反应中的不同催化性能, 从而 确定该容量. 该方法避免了湿浸初期反离子对金属负载的影响, 最终可应用于多种不同的金属. 结果表明, 该技术可跟踪 氧空位浓度和表面氧含量的变化趋势, 有望成为一种定量测定载体单原子稳定容量的新方法.

关键词: 氧化铈; 单原子催化剂; 氧空位; $\mathrm{CO}_{2}$ 加氢; 再分散

收稿日期: 2019-08-01. 接受日期: 2019-09-12. 出版日期: 2020-06-05.

*通讯联系人. 电子信箱: mcargnello@stanford.edu

†共同第一作者.

本文的电子版全文由Elsevier出版社在ScienceDirect上出版(http://www.sciencedirect.com/science/journal/18722067). 